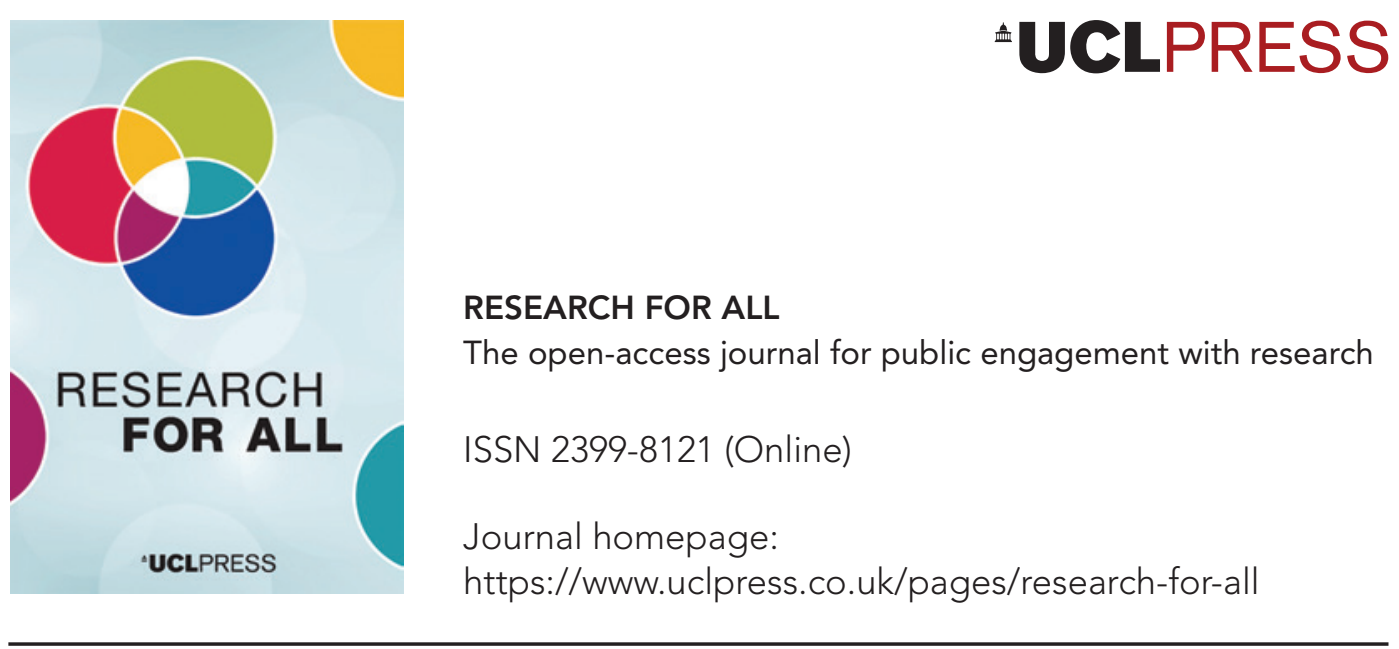

\title{
Research, \#Huh? Improving research awareness in NHS Grampian through a website and more
}

\section{Emma Berry and Mariella D'Alessandro}

\section{How to cite this article}

Berry, E. and D'Alessandro, M. (2020) 'Research, \#Huh? Improving research awareness in NHS Grampian through a website and more'. Research for All, 4 (2), 180-93. Online. https://doi.org/10.14324/RFA.04.2.04

Submission date: 10 May 2019

Acceptance date: 19 December 2019

Publication date: 22 September 2020

\section{Peer review}

This article has been peer-reviewed through the journal's standard double-blind peer review, where both the reviewers and authors are anonymized during review.

\section{Copyright}

(c) 2020 Berry and D'Alessandro. This is an open-access article distributed under the terms of the Creative Commons Attribution Licence (CC BY) 4.0 https://creativecommons.org/licenses/ by/4.0/, which permits unrestricted use, distribution and reproduction in any medium, provided the original author and source are credited.

\section{Open access}

Research for All is a peer-reviewed open-access journal. 


\title{
Research, \#Huh? Improving research awareness in NHS Grampian through a website and more
}

\author{
Emma Berry* and Mariella D'Alessandro - NHS Grampian Research and \\ Development, Aberdeen, UK
}

\begin{abstract}
Our public-facing website \#Huh (Helping U Help) - www.grampianclinicalresearch. com - has been designed to engage public, patients and staff in clinical research. We have included views from patients and the public in its design and content, using multiple methods to gather feedback, some proving more successful than others. This article presents how our website was developed, including the different methods we used to gather views from the patients and public before, during and after its development. We hope that this paper will give useful insights to other people interested in incorporating stakeholder feedback into their own work.
\end{abstract}

Keywords: NHS Grampian, clinical research, \#Huh, evaluation, website development, stakeholder engagement

Key messages

- Regional health services can encourage public and patients to become involved in local clinical research initiatives and to give feedback about them.

- Limited resources in public engagement and involvement require making the most of existing local teams and networks.

- A template for evaluating 'engagement and involvement activities' can draw out the learning accrued from various local populations, with different methods.

\section{Background}

Clinical research underpins most advances in health care. Thanks to clinical research, we can get access to new, safe, cutting-edge clinical treatments and medical devices (HRA, 2020). Clinical research also plays a vital role in the development of medicines to control diseases, in treating chronic or degenerative conditions and in improving people's health (ibid.).

The modern health-care shift from a 'one size fits all' approach to 'personalised medicine', where the best possible treatment is 'tailored' to every patient's needs, has led to a dramatic increase in the number of clinical research studies, throughout the UK and worldwide (NHS England, 2016: 6, 7).

However, public perception of clinical research can be quite negative, with media often portraying research participants as 'guinea pigs', with little control over the studies in which they are taking part. This misconception can have a negative effect on the decision whether to participate in clinical research (Walsh and Sheridan, 2016). 
In recent years, there has been an increasing effort to change this negative view. Previous work by the National Institute for Health Research (NIHR), as part of their It's Okay to Ask campaign, showed that only 21 per cent of the public would feel comfortable to enquire of their health-care team about clinical research opportunities (NIHR, 2013). The campaign encouraged the public to ask about getting involved in research by using different channels such as television, radio, social media and a website. The authors felt that there was good engagement with the campaign, due to the positive feedback they received, but they found it hard to give an exact figure for the number of people reached. They do state that 229 people completed their survey, and they distributed forty thousand leaflets and five thousand clinician cards, as well as numerous other resources. However, it was concluded that both public and staff should have been equally targeted, so as to have more impact (ibid.).

Recently, there has been a significant increase in the number of patient and public involvement (PPI) groups, in recognition of the importance of involving patients and public in the design of valuable and effective clinical research (Wilson et al., 2015). This has also been highlighted by the publication of the National Standards for Public Involvement in Research (Public Involvement Standards Development Partnership, 2018). Many research funding bodies now require evidence of public involvement at the grant application stage, and a commitment to continue PPI throughout the course of the study. One example of this is the charity Diabetes UK, whose grants advisory panel reviews research applications from a patient and carer perspective (Diabetes UK, n.d.). The establishment of resources such as SHARE (Scottish Health Research Register), and its proactive attitude towards participants' recruitment, has allowed more individuals to become engaged with research (SHARE, 2020). SHARE is an NHS Research Scotland initiative, created to establish a register of people interested in participating in health research and who agree to allow SHARE to use their coded data in their various NHS computer records to check whether they might be suitable for health research studies. If invited to take part in a health research study, SHARE members can decide if they want to participate or not; they can also easily opt out of this registration scheme, if they change their mind (ibid.).

However, there is still a consistent number of people who do not know what clinical research is and why it is needed. We believe that research is for everyone, and we want to ensure that individuals have an equal opportunity to become involved. We feel that a shift in the perception of clinical research, through increased awareness and understanding, is paramount to the promotion of clinical research opportunities and involvement.

We have been working on a programme to improve public awareness, understanding and involvement in clinical research in Grampian, and have developed building tools to support this programme. Our project has focused primarily on a website, funded by the Chief Scientist Office (CSO), which we are using as a platform to promote public engagement in clinical research. Members of the public, research participants and staff were involved in the design of this website and its tools.

\section{\#Huh, research? A website and more}

In March 2019, we launched the NHS Grampian research awareness website: \#Huh (Helping U Help) - www.grampianclinicalresearch.com. This website contains various tools to improve awareness and understanding of research, including:

- an animated video on clinical research

- video experiences from research staff and participants 
- frequently asked questions (FAQ) about clinical research

- a research studies database

- an events section

- a news section

- external links for more information

- an interactive game.

In addition, we have produced posters to promote the website (see Figure 1), and leaflets that provide our website FAO section in printed form. These resources are currently displayed in various locations across NHS Grampian.

We are also promoting our work through social media channels and have tagged our Twitter account to other relevant accounts, within and outside NHS Grampian, to increase the number of viewings.

\section{NHS Grampian and its population}

NHS Grampian has been in operation since April 2004, taking over from Grampian's two previous NHS trusts (NHS Grampian, 2020). This organization serves over half a million people, spread across the North East of Scotland, including the areas of Aberdeen City, Aberdeenshire and Moray (ibid.). The large geographical size of Grampian creates a unique challenge to the delivery of effective health services compared to other areas of the UK. We are also mindful that some of the more rural areas in our health board may not have reliable internet access or no access at all (Philip et al., 2015; Scottish Government, 2019). We have tried our best to ensure that this does not prevent us promoting research awareness, but we have not been able to replicate all the elements of the website in print form, such as the research projects database, which is updated on a monthly basis, the interactive game and the videos.

\section{Involvement: Who, why, when, how, where?}

Our project is strongly focused on engaging and involving stakeholders. We have used various methods to gather opinions from patients and members of the public throughout our project. Our engagement and involvement activities were shaped by the limited resources and time available. Table 1 details the engagement undertaken during the project and highlights the important information gathered, including the evaluation of each activity and the learning achieved. This table could be used as a template by other teams who wish to share the key highlights of their work, rather than providing multiple reports to share with colleagues.

\section{Surveys for communication and direction}

Our first activity was an anonymous public survey to gather baseline information on current research engagement. We wanted to understand the current situation so that we could evaluate the impact of our project. We also used the replies from this survey to establish the content of our clinical research awareness website, and to decide on the best methods to promote it.

The survey asked a variety of questions, including whether respondents had heard of clinical research previously, if they had been involved or would consider taking part in clinical research, and if they would be interested in finding out more information about it. Depending on the answers provided, further questions were prompted to 
Figure 1: Poster promoting the website

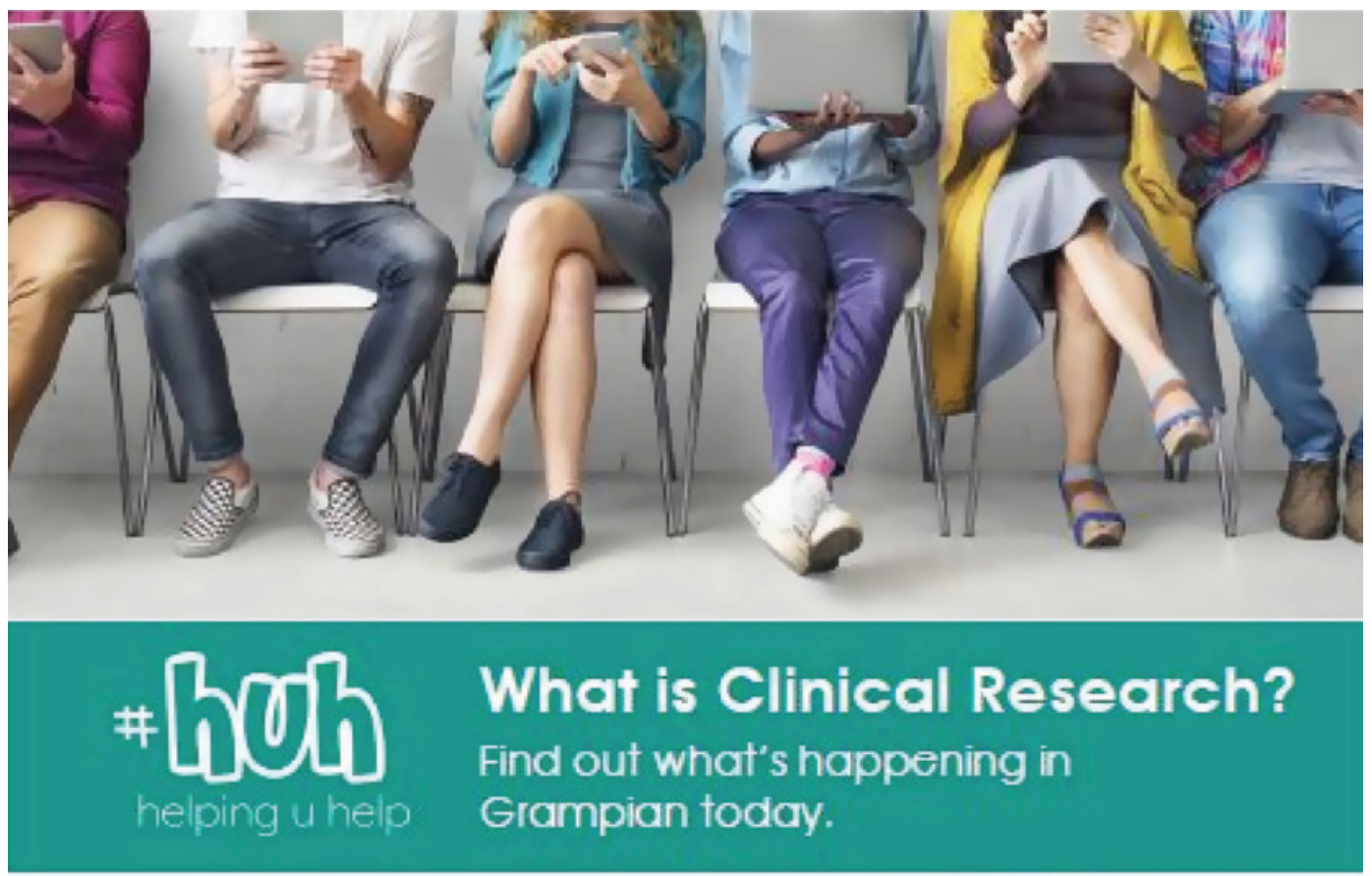

Scan here or $\log$ on to our website to learn more about what we are doing.
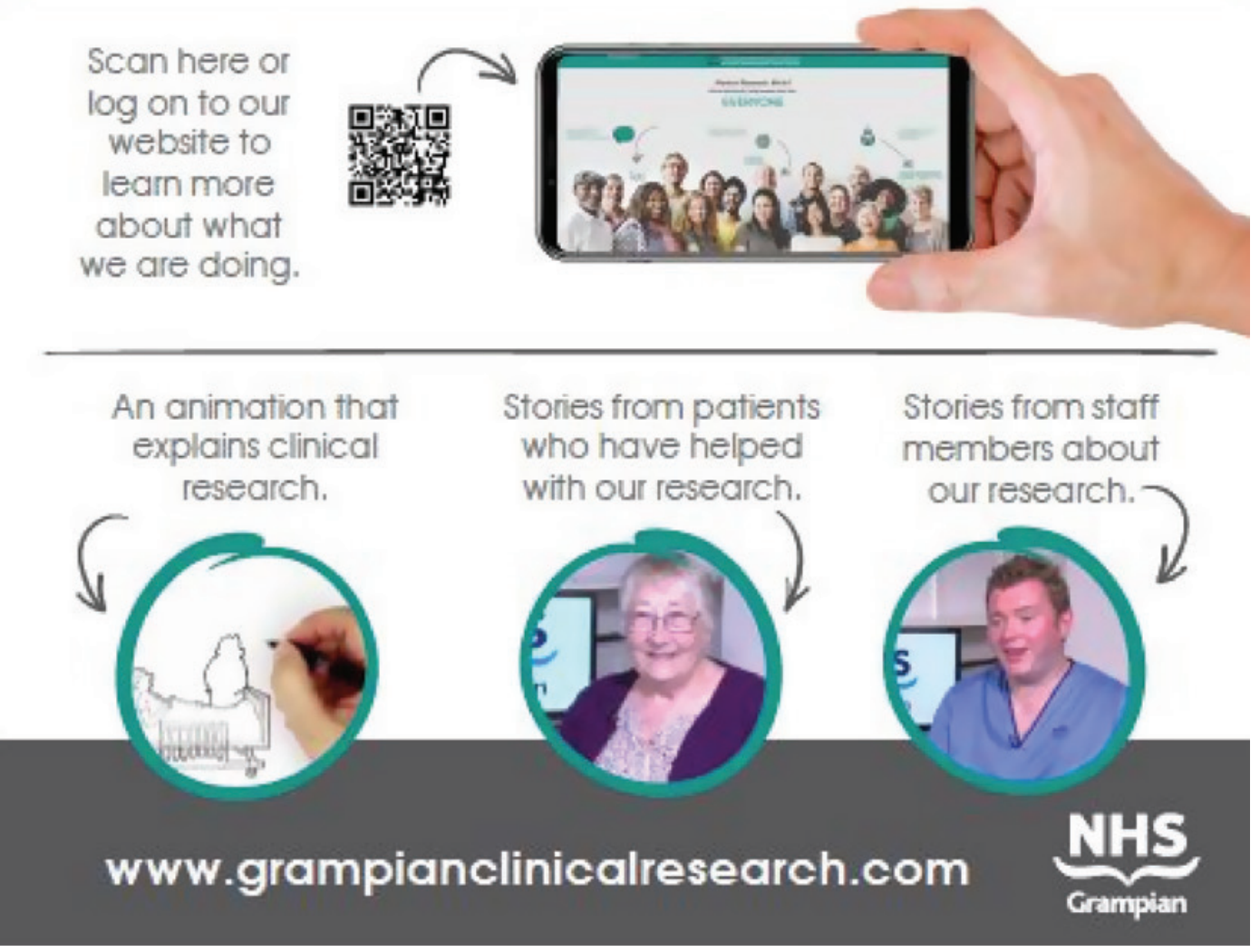

gather additional information, such as what the respondents would be interested to hear about research or how they had been previously involved in research. The survey also asked them their age range and what was their preferred communication channel. Most questions offered predetermined answers to select from (for example: yes, no, maybe), but there were also some open questions, so any additional relevant information could be provided. 


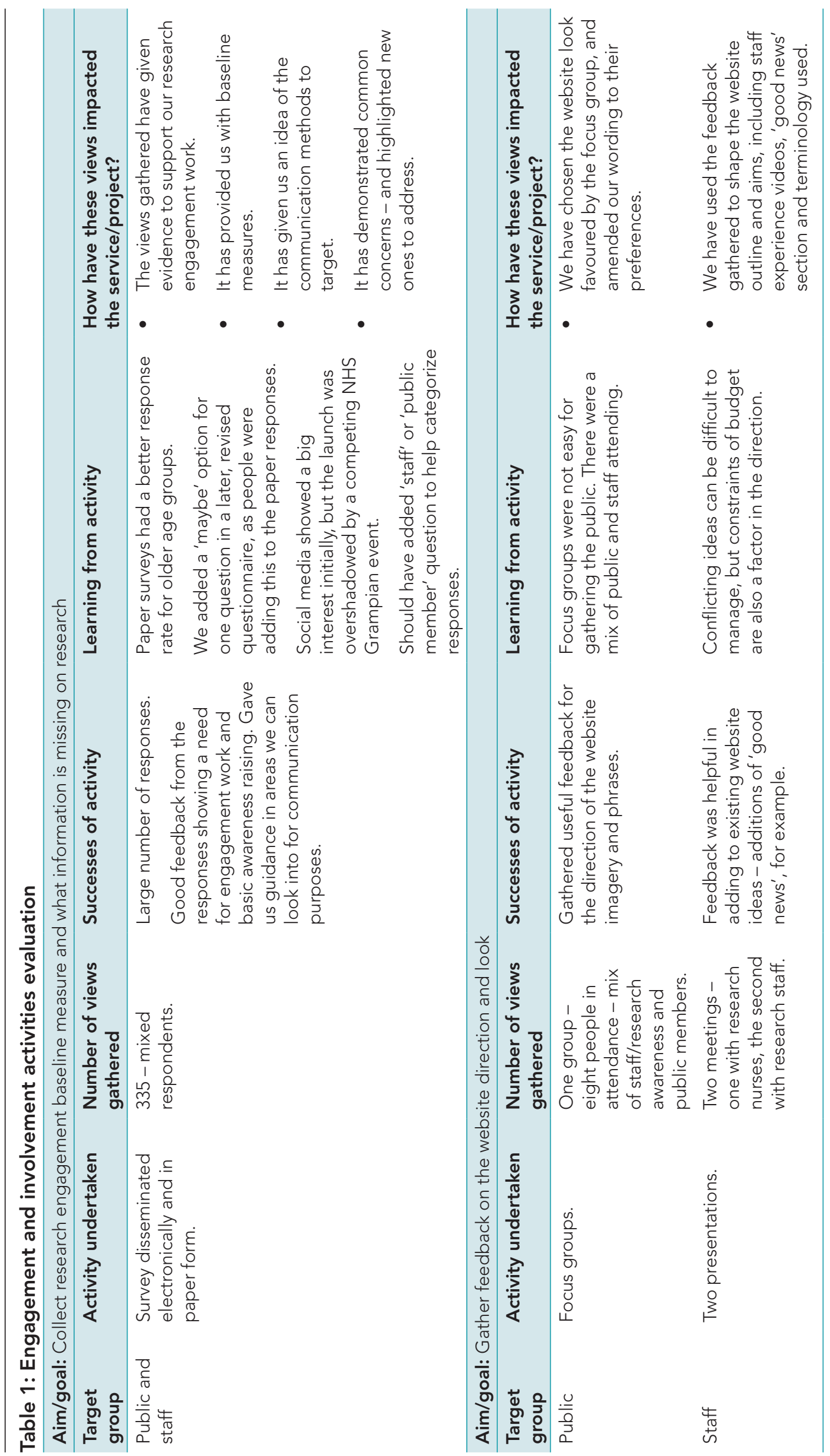




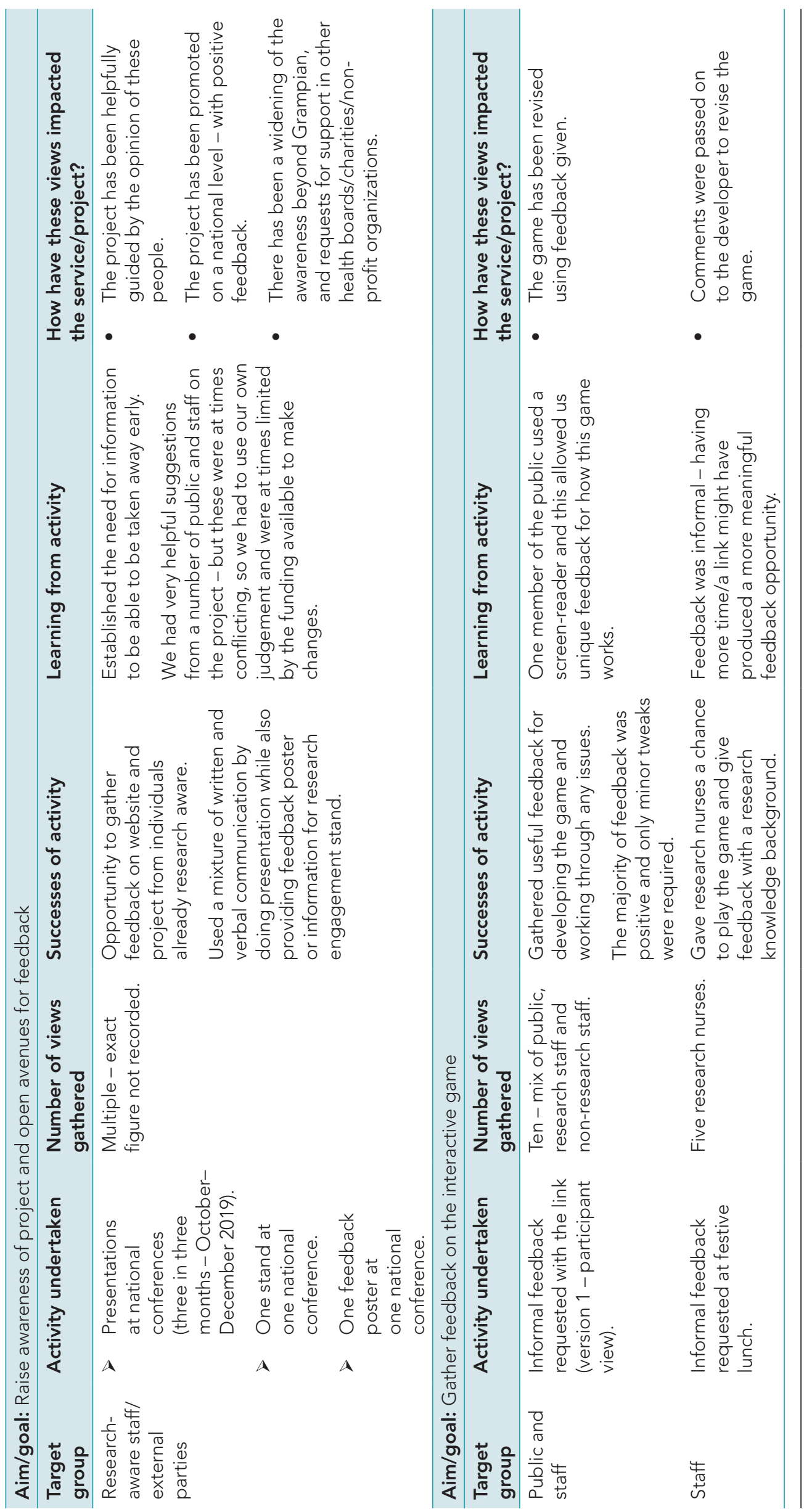


The link to the electronic version of the survey was disseminated across NHS Grampian and local universities through social media, email and internal communications. We also created a paper version of it, to avoid discrimination against individuals who did not have internet access, and distributed copies across the hospital sites. We arranged for staff to return completed surveys via the internal mail.

This survey ran from 13 September 2018 to 16 October 2018, and gathered 335 responses (206 electronic and 129 paper). This was the largest response we had to any of our engagement activities, probably because we used a range of dissemination methods, including the social media channels of our organization, existing email networks and paper copies in hospital clinics. We deliberately made the survey as short as possible to ensure people were not put off by its length.

The survey results showed that although many respondents had heard of clinical research, most of them had never been involved in it. However, 72 per cent of the respondents said that they would probably take part in clinical research if offered the opportunity, and 70 per cent were interested in getting more information about it. This clearly indicated that there was an interest, and potential, for more patients and members of the public to become involved across Grampian. A detailed summary of the survey results is available (Research Awareness Team, NHS Grampian Research and Development, 2018).

\section{Focus group to focus on design}

We felt that it was extremely important to gather public opinion about how our website should look. With the help of our colleagues in the NHS Grampian Public Involvement Team, two focus groups were organized for September 2018, at scheduled times, outside traditional working hours. An open invitation was sent out to members of the public through NHS Grampian internal and external channels.

The focus groups did not attract as much interest as we had hoped, so one date had to be cancelled. The eight people who attended the group were a mix of staff and public. The venue was easily accessible, and we offered refreshments at the event. We showed the attendees posters that illustrated the two potential designs for the website created by our website developer. The group discussed the website appearance, structure and terminology, and one design was unanimously picked as a favourite. The focus group members were also asked to anonymously complete a website comparison sheet, so we could capture their individual opinions (see Box 1). The information we gathered was invaluable, and we used the design picked by the group for our website. However, this method of engagement did not attract as much interest as we would have expected. In future, a drop-in style session might have a higher engagement than scheduled focus groups, as this would allow for more flexibility for potential attendees.

\section{Meetings for feedback}

We felt that staff should have the opportunity to give their input on the design and content of the website, so we organized two sessions for them. At both sessions we delivered a presentation, with a draft plan of our website content and tools.

A pool of 15 NHS Grampian research nurses attended the first presentation and gave us invaluable inputs from their experience of working with research participants on a regular basis. The second presentation was held as part of the NHS Grampian Research and Development Lunchtime Seminar Series; sessions are regularly attended by between thirty and forty staff members from NHS Grampian and the University of Aberdeen. 
Box 1: Focus group written feedback form

\section{Website option A}

- What is your first impression of website A?

- What message do you think is being conveyed in website $A$ ?

- What do you like or dislike about the website?

\section{Website option B}

- What is your first impression of website $B$ ?

- What message do you think is being conveyed in website B?

- What do you like or dislike about the poster?

For our website, please circle which option you prefer on each line:

Cartoon look

A big group of different people

One page that scrolls down for the information

More videos of patients' experiences
Real people

A family with different generations

You click into different pages for information

More videos about research terms and words

There were many helpful ideas and comments from both sessions, which were incorporated into the website, including suggestions to:

- share 'good news' stories about research

- use clear and understandable language

- explain why we do medical research

- highlight the vast experience of our research staff.

These sessions were useful for gathering feedback from staff with relevant medical research experience. However, we received more useable feedback from the smaller meeting with the research nurses, possibly because it was more informal and all the nurses knew each other, so they felt more comfortable making suggestions (Holloway and Galvin, 2017: 131). They gave us ideas on the type of stories that we could report as 'good news', and told us of the common misconceptions that patients and public had about their role, and about medical research in general. (For example, some patients thought that a research nurse was a trainee nurse rather than a specialized role.) The larger presentation was more formal, and the feedback and discussions were more focused on the language used in the website and the financial implications of such a project. Our advice for others planning a similar activity is to organize smaller and informal meetings, which can lead to a more extensive discussion and a higher number of suggestions, compared to a larger, more formal seminar.

\section{Presentations at conferences: Another opportunity for feedlback}

As our website developed, we were able to present a draft and some of its tools at three conferences:

- NHS Research Scotland Conference in October 2018

- NHS Grampian Research and Development Conference in December 2018

- Scottish Research Nurse and Coordinators Network (SRNCN) Conference in December 2018. 
These conferences allowed us to gather feedback from colleagues and members of the public, who attended from across Scotland. We received various comments and queries during the question and answer sessions. We also offered the opportunity for delegates to provide informal feedback on Post-it notes during breaks. We received many positive comments on the animated video, which we shared with other boards to be used in their own areas. We also had questions about the accessibility of the website information for people who do not have access to a computer, which supported us further to produce and print our FAQ leaflet.

The suggestions collected at these events were fewer than the ones from other involvement activities, but they were extremely useful and included points that we had not considered before. These presentations also allowed us to liaise with colleagues working in research engagement and involvement across Scotland, which has helped us moving forward with our project. From our experience, we learnt that presenting work at meetings, when it is still at draft stage, is extremely valuable, because it can lead to very constructive comments from colleagues working in the same field.

\section{Electronic feedback for an electronic game}

Our website also hosts an innovative 'participant experience' interactive game, which illustrates, in a friendly way, a participant's journey through a clinical research study. Game players can choose from three types of study:

- investigation of a medicinal product

- a study of a new device

- observational.

This game has been developed 'in-house', with the support of the NHS Grampian Learning and Development Team. We had originally planned this to be an eLearning module for staff, but many staff struggle to find time to do online training (Quinn, 2018). We also thought that, given that the aim of the project was to increase patient and public awareness of medical research, such a game would be better suited for open access through our website. This also allowed us to give it a more interesting and engaging format.

Through this game, we wanted to show the essential requirements of a clinical research study, including the participant information sheet, informed consent and different types of research assessments (such as questionnaires and clinical measurements). We also wanted to highlight that there are many various, highly qualified staff who may get involved in a research study, such as nurses, pharmacists and allied health professionals, as well as doctors. In addition, we felt it was important to highlight that research participation is voluntary, so we introduced the 'withdraw' option to every step of the game. Screenshots of the game can be seen in Figure 2, and you can see the game itself at https://grampianclinicalresearch.com/game/story_ html5.html.

Once created, we asked colleagues to test the draft game to ensure that our research games resembled a suitable research project and were clear, accurate and easy to follow. We are now in the process of adding the option to play as a researcher, so people can experience the same studies from a different perspective.

Due to tight deadlines, we had limited time to gather feedback on the game, so we decided to use a more informal method, by emailing already existing networks including our staff and the NHS Grampian Public Involvement Network. We were able to engage with a diverse range of members of the public who were interested in the work of NHS Grampian and did not have previous research experience to our 
knowledge. Although this method may not be ideal for all engagement activities, we had a good level of feedback and extremely valuable comments, which helped to ensure that our game was suitable. Overall, people enjoyed playing the game, and the majority of comments were positive. The main suggested changes were about accessibility - to ensure that all individuals could read and understand the game, regardless of any visual impairment issues.

We have also encouraged people to come back with further comments after the game was launched on our website, and we have been advised that colleagues

Figure 2: Screenshots from the online game - a: Welcome screen of the game; b: Select a study screen with three study options; c: A research scan being carried out

a

\section{Welcome to Research Your Study

This is a simulation to raise awareness of clinical research within Grampian. This is not a real clinical research study or project.

\section{Let's get started}

Note: nothing that you select, choose or type into this simulation will be

recorded outside of the duration of you accessing this resource, and

nobody else will be able to read or access any responses you give to any

part of the simulation.

b

\section{Select a study}

This study is an investigation of a new medicine, click on the title of study to select that one.

Withdraw
To investigate a new medicine "SuCAr' in reducing pain during headaches

To observe the EAting habits between hospital in-patients who watch Baking Shows and those who do not. -The EABS study

SKELApp: A study into a new handheld device application for $\mathrm{x}$-rays 


\section{Figure 2: continued}
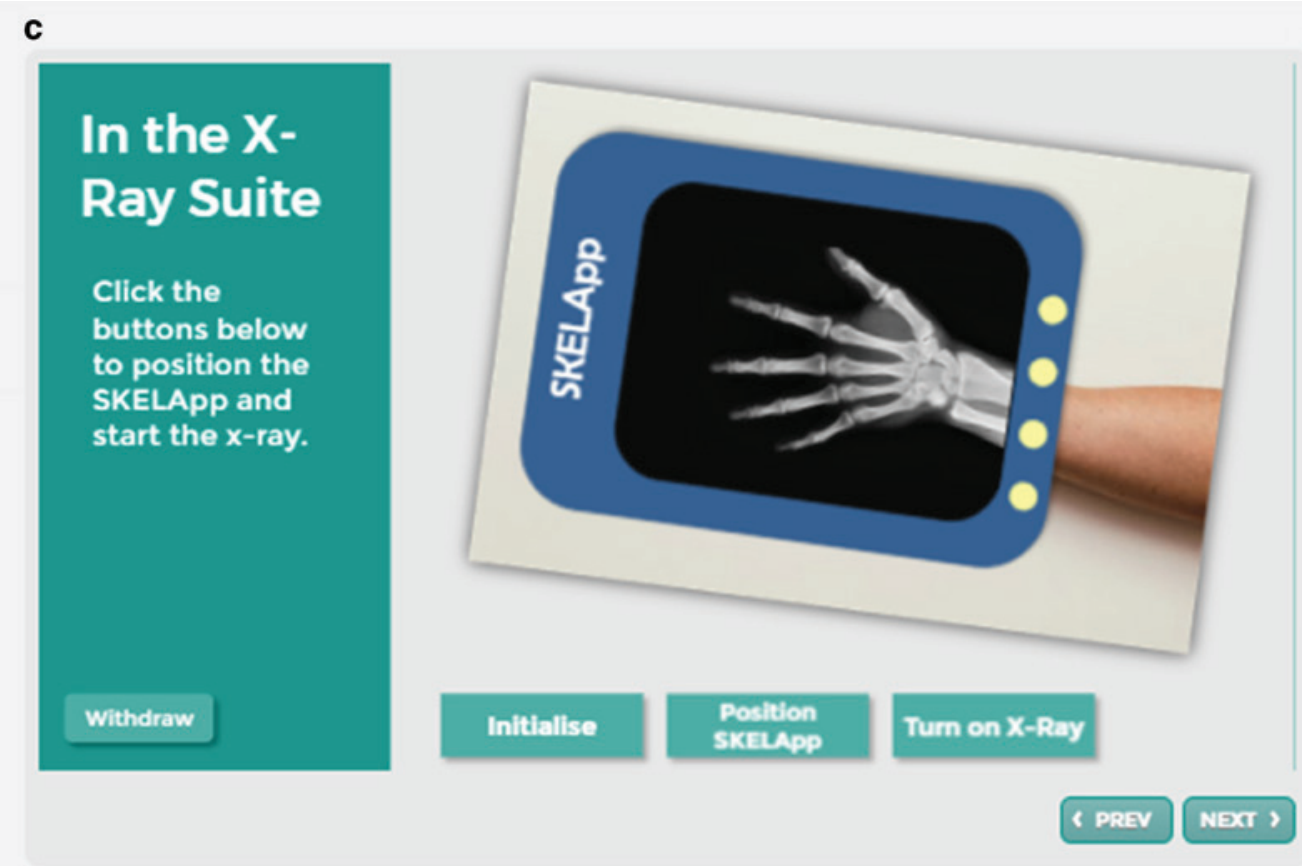

Source: www.grampianclinicalresearch.com

in other NHS organizations have used our game to introduce research to children. Although this was not our intended audience, we are delighted that other boards are able to use this resource, and that it is simple enough for children to understand.

\section{Challenges we faced}

The opportunity to promote why we do clinical research, and its importance for the future of health care, has made this the first venture of its kind in NHS Scotland. In undertaking this project, we had limited resources and tight deadlines, and therefore we had to be realistic about what we could achieve. For this reason, we could not implement all the suggestions received from our stakeholders, and we had to be very careful about how we managed expectations. The suggestions that we were unable to implement were generally extra elements on the website, or the creation of tools requiring additional external resources or staff capacity, such as a printout version of studies currently open to recruitment. However, we did our best to implement all the feasible suggestions. We found that involving staff and members of the public from an early stage had a very positive impact on our project, ensuring that our website and tools were appropriate for our target audience.

We worked with numerous individuals and departments to be guided on our journey, and we sought out advice from experts about how to undertake our tasks. This project has allowed us to promote collaborative working and to develop good working relationships with various organizations. All of these collaborations have been vital for the success of our project and for our future work.

The fact that we were provided with funding for the website allowed us to commission an external provider to help with its design and implementation. However, the development of additional tools and all the advertisement and promotion work for 
the website was done in-house, which created additional work for our NHS colleagues in several departments. We would have been unable to do this without their support, and we were extremely lucky that they were able to help us. For others embarking on a similar project, the labour and finances could present a challenge. We would strongly recommend discussing your work at an early stage with any departments from which you may require support for your project, to ensure they are able to provide the help you need and to discuss any financial implications.

\section{What has happened since the launch, and what next?}

We have been evaluating the impact of our website through social media monitoring, Google Analytics and feedback surveys. Unfortunately, due to an error in the website hosting, we were only able to track website traffic from 10 April 2019. Between 10 April and 1 May 2019, we had 171 website views from 148 users. The website tends to have lower traffic at weekends, and our peak traffic times seem to be linked to our social media activity. This will be a key aspect for our website promotion, moving forward. Our most viewed pages are the database of studies open for recruitment in NHS Grampian and our FAQ section. Although we are disappointed that we were not able to see the impact of the launch of the site on website views, the website traffic during April is a more realistic estimate of an average month. However, we have found that the promotion of our staff successes and experiences, as well as attending engagement events in the community, have translated into increased views. During September 2019, we took part in a local engagement event, and posted and tweeted the stories of the research experience of a local team member and the success of one of our research teams. This resulted in 464 views of our website from 403 visitors.

We have also been monitoring the YouTube video analytics, in response to our social media posts. Our most viewed video is consistently an animation (www.youtube. $\mathrm{com} /$ watch? $\mathrm{v}=\mathrm{VDdWj8AHdO4}$ ), with the remaining videos in the top five being from NHS Grampian staff. We will continue to monitor this channel to see how we can diversify and include relevant videos in the future.

We have also posted a survey within the website for individuals who wish to provide feedback on the website itself and help in the development of its future content. The survey was made available on 2 April 2019 in the external links section, and as a news post on the website, and it was promoted through our organizational social media channels.

We have only had one response in the first few months, and we were unsure if this is due to the website being new and still gathering awareness, or if this feedback link is not visible enough. Although our single response was very positive, we aimed to increase the uptake of this feedback opportunity, and we used engagement events as an opportunity for feedback. We have since had more people provide feedback on the website and will continue to promote opportunities for feedback.

Recently, we have been attending various engagement events within and outside NHS Grampian to promote our website. We have taken part in the local university MayFest and Explorathon, which are public research engagement events well attended by the local communities. We also continue to present our work to colleagues and collaborators at local and national events, such as the Grampian Ageing Research Network (Aberdeen, September 2019) and the UK Clinical Research Facilities Conference (Nottingham, July 2019). The links and collaborations we have established with our colleagues in the University of Aberdeen and Robert Gordon 
University, as well as with other organizations across Scotland and other parts of the UK, have been pivotal in our engagement activities. We are also working to support researchers undertaking patient and public involvement in their research. Our website will be used as a platform for people to learn more about clinical research, and to offer opportunities to become more involved.

In conclusion, we have found that public and patient involvement is a vital resource for shaping our website and its tools. This project was an opportunity for our team to grow and expand our understanding of research engagement. As such, we have key learning points for other teams considering similar work in the future:

1) Regional health services can encourage public and patients to become involved in local clinical research initiatives, and to give feedback about them. Not every way of gathering feedback is going to be successful, however. For us, it was a real challenge finding people to attend focus groups, but we got better engagement through a quick survey. Using a range of methods allowed us to gather a range of views from different groups.

2) Limited resources require making the most of existing local teams and networks. Working with existing networks and departments can save time, money and stress. We developed our online game in-house, but our website had to be commissioned externally due to time limitations. It is essential to communicate with the teams involved as early as possible, to avoid giving them excessive workloads or unrealistic expectations.

3) A template for evaluating 'engagement and involvement activities' can draw out the learning accrued, with different methods, from various local populations. However, a continuous evaluation of the impact of the engagement methods used is essential, otherwise the feedback gained might not be a true representation of what the stakeholders really think, making it a waste of time and money.

Looking forward, we will continue to encourage everyone to share their feedback, and to suggest how to develop our tools to fit their needs. We will be looking to share our learning with others, and to use what we have learnt so far to guide our next steps. This will include supporting more opportunities for patient and public involvement in research across Grampian.

\section{Acknowledgements}

We would like to thank all of the public, participants and staff who have helped with this work, both in Grampian and across Scotland. Their support and help have been invaluable. We would also like to thank the Chief Scientist Office for funding the creation of the website.

\section{Notes on the contributors}

Emma Berry is a study support facilitator at Research and Development, and was a public involvement officer at Corporate Communications, with NHS Grampian. She is now studying for a PhD in health services research. She has a master's degree in health services and public health. She is passionate about engagement in both health-care services and health-care research. She believes that collaboration between organizations, patients and the public is key for the future of health-care systems. 
Dr Mariella D'Alessandro has a PhD in genetics, and worked for ten years as a postdoctoral researcher on the genetics of epithelial diseases. From 2010 to 2015, she was a clinical research associate for NHS Grampian, and consequently got her current job as clinical research facilities manager at NHS Grampian. For the past two years she has also been supporting the clinical research awareness project.

\section{References}

Diabetes UK (n.d.) 'Patient and public involvement (PPI) in your study'. Online. www. diabetes.org. uk/research/for-researchers/apply-for-a-grant/help-with-involving-participants (accessed 26 July 2018)

Holloway, I. and Galvin, K. (2017) Qualitative Research in Nursing and Healthcare. 4th ed. Chichester: Wiley.

HRA (Health Research Authority) (2020) 'UK policy framework for health and social care research'. Online. www.hra.nhs.uk/planning-and-improving-research/policies-standards-legislation/ukpolicy-framework-health-social-care-research/ (accessed 29 May 2020).

NHS England (2016) Improving Outcomes through Personalised Medicine: Working at the cutting edge of science to improve patients' lives. London: NHS England. Online. www.england.nhs.uk/ wp-content/uploads/2016/09/improving-outcomes-personalised-medicine.pdf (accessed 3 May 2019).

NHS Grampian (2020) 'About NHS Grampian'. Online. www.nhsgrampian.org/nhsgrampian/gra_ display_hospital.jsp?pContentID=1631\&p_applic=CCC\&p_service=Content.show\& (accessed 30 May 2020).

NIHR (National Institute for Health Research) (2013) It's Okay to Ask Summary Report.

Philip, L.J., Cottrill, C. and Farrington, J. (2015) "“Two-speed" Scotland: Patterns and implications of the digital divide in contemporary Scotland'. Scottish Geographical Journal, 131 (3-4), 148-70. Online. https://doi.org/10.1080/14702541.2015.1067327

Public Involvement Standards Development Partnership (2018) National Standards for Public Involvement in Research. National Institute for Health Research. Online. www.invo.org.uk/wpcontent/uploads/2019/02/71110_A4_Public_Involvement_Standards_v4_WEB.pdf (accessed 26 July 2018).

Quinn, K. (2018) 'Plenary Session B3: Realising the potential of digital learning'. Paper presented at the NHS Scotland Event 2018, Glasgow, 18 June 2018.

Research Awareness Team, NHS Grampian Research and Development (2018) NHS Grampian Research Awareness and Engagement Report: A short summary of our survey findings. Online. www.nhsgresearchanddevelopment.scot.nhs.uk/wp-content/uploads/2019/05/NHS-GrampianEngagement-in-Research-Report-October-2018.pdf (accessed 28 June 2020).

Scottish Government (2019) 'Scottish Household Survey 2018: Annual report'. Online. www.gov. scot/publications/scotlands-people-annual-report-results-2018-scottish-household-survey/ (accessed 25 October 2019).

SHARE (Scottish Health Research Register) (2020) 'What is SHARE?'. Online. www.registerforshare. org/ (accessed 30 May 2020)

Walsh, E. and Sheridan, A. (2016) 'Factors affecting patient participation in clinical trials in Ireland: A narrative review'. Contemporary Clinical Trials Communications, 3, 23-31. Online. https://doi.org/10.1016/j.conctc.2016.01.002

Wilson, P., Mathie, E., Keenan, J., McNeilly, E., Goodman, C., Howe, A., Poland, F., Staniszewska, S., Kendall, S., Munday, D., Cowe, M. and Peckham, S. (2015) 'ReseArch with Patient and Public invOlvement: A RealisT evaluation - the RAPPORT study'. Health Services and Delivery Research, 3 (38). Online. https://doi.org/10.3310/hsdr03380 